\title{
Conservative orthopaedic treatment
}

\author{
Jean-Claude de Mauroy \\ From 7th International Conference on Conservative Management of Spinal Deformities \\ Montreal, Canada. 20-22 May 2010
}

Some scoliotic curves are developing into adulthood, mostly by lumbar discal decompensation and sometimes with evolving rotatory dislocation well described by Jean Dubousset.

The Lyonaise conservative orthopaedic management is a protocol used for our patients for over 60 years.

It consists of:

$1^{\circ}$ ) A lumbar plaster cast is taken, usually in standing position, over 3 weeks. This plaster cast is taken in lordosis with correction of the head offset. (Figure 1)

$2^{\circ}$ ) Wearing a high-density polyethylene bi-valve overlapping shell brace for at least 4 hours a day. (Figure 2)

$3^{\circ}$ ) Physiotherapy whose main aims are for pain relief and posture re-education.

Here are the results of 33 degenerative scoliosis patients (30 women and 3 men), controlled for at least 5 years after the beginning of the treatment.
The average age in the beginning of treatment is 60 years. In every case the pain and the posture improved.

In 31 cases out of 33, the Cobb's angle was stabilized.

5 years after commencing treatment, half of the patients are continuing to wear the brace for more than 4 hours a day.

Placing a patient in a plaster cast is an indispensable prerequisite for this treatment. Besides the therapeutic role of musculo-ligamentous adjustment of paravertebral tension, it is also a test. The patient must be pain free while pursuing normal activities.

\section{Conclusion}

These results are comparable to those obtained by the other teams, who in France are using an identical
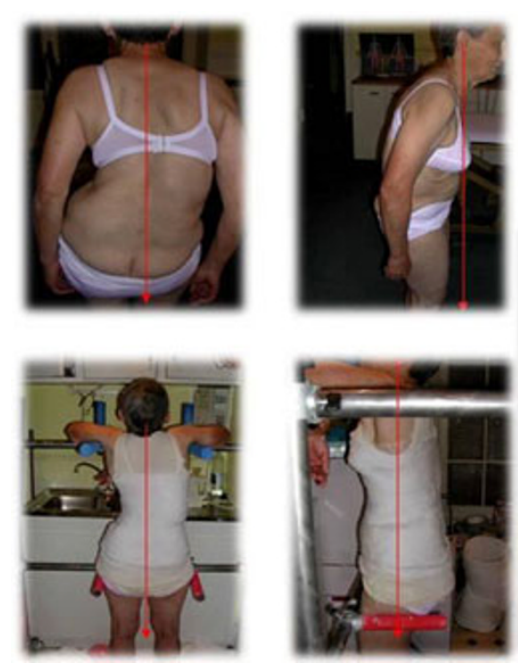

\section{Frame for adult scoliosis}

Figure 1

Clinique du Parc, Lyon, France

protocol.

Full list of author information is available at the end of the article
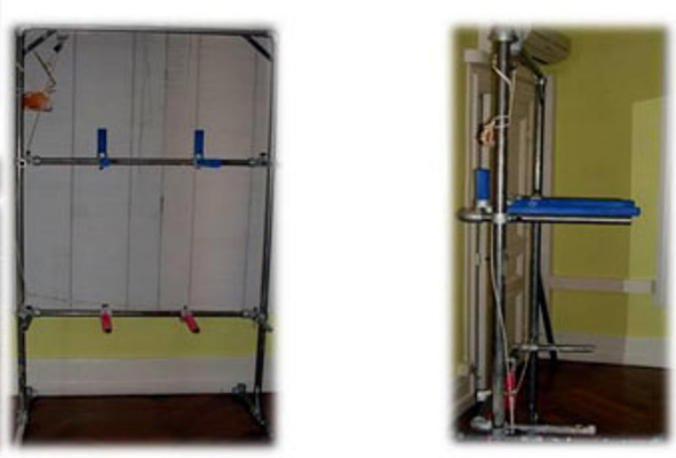


\section{polyethylene bi-valve overlapping shell brace}
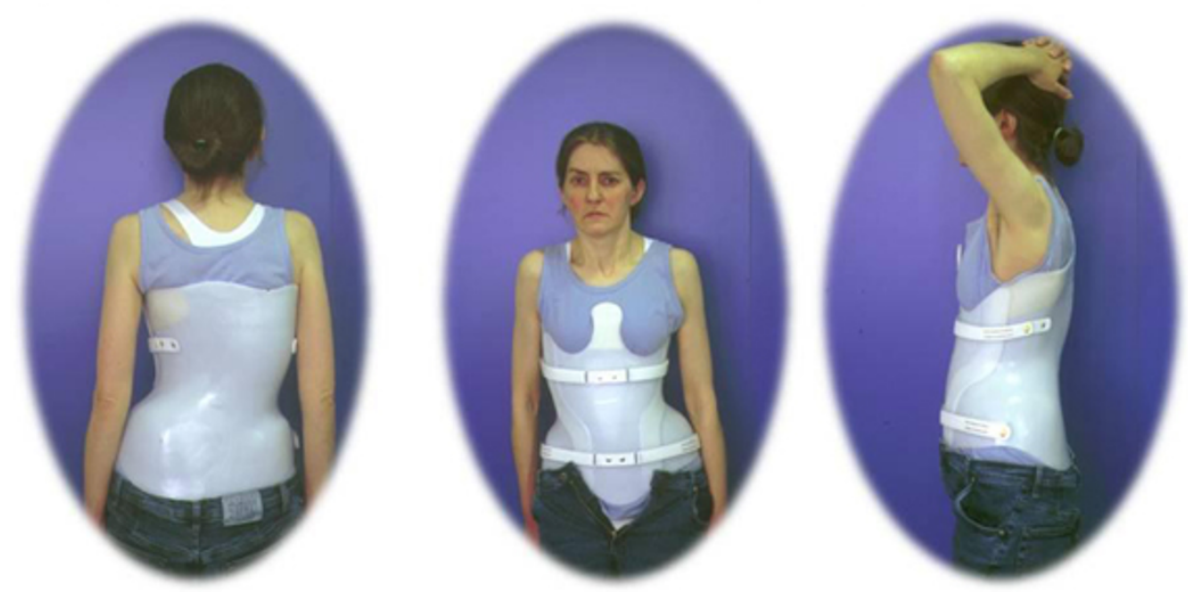

Figure 2

Initially reserved for the most severe cases, this protocol deserves to be more widely used for adult scoliosis.

Published: 10 September 2010

doi:10.1186/1748-7161-5-S1-046

Cite this article as: de Mauroy: Conservative orthopaedic treatment.

Scoliosis 2010 5(Suppl 1):046.

Submit your next manuscript to BioMed Central and take full advantage of:

- Convenient online submission

- Thorough peer review

- No space constraints or color figure charges

- Immediate publication on acceptance

- Inclusion in PubMed, CAS, Scopus and Google Scholar

- Research which is freely available for redistribution 